\title{
Research on the Reform and Innovation of Vocal Music Teaching in Colleges
}

\author{
Lei Fu
}

Yangtze University School of Arts, Jingzhou, Hubei, China

\begin{abstract}
The fundamental purpose of education is to promote better development of students. As the process of economic globalization accelerates, the teaching methods of art courses are also constantly improving. Especially in today's society with a high degree of tolerance, science and technology and the internet have not only changed people's lives, but also changed the mode of thinking and learning. As an important front for transporting talents, the school pays more attention to strengthening the construction of student quality education and professional education service system. Obviously, the traditional education model can no longer meet the current social development's demand for high-quality talents. If we want students to achieve better development, we need to actively embrace the changes of the times, be student-oriented, follow the trend, and formulate educational policies that are more in line with the development of the times. Therefore, we need to make drastic reforms and innovations in vocal music teaching, and continuously improve the quality and level of vocal music teaching by reconstructing the teaching model. This article briefly describes the positive significance of the current college vocal music teaching reform and innovation, as well as the specific reform and innovation strategies for reference.
\end{abstract}

Key words: colleges; vocal music teaching; reform and innovation; approach explore

\section{Introduction}

The continuous deepening of the new curriculum reform puts forward brand-new requirements for the goals and methods of education and teaching. Under the new situation of the rapid rise of emerging technologies, the teaching concept based on quality education is subverting the traditional examination-oriented education thinking. As an important position for cultivating socialist successors, the school must implement the socialist school-running policy into specific subject teaching. And the so-called all-round development not only refers to the mastery and accumulation of cultural knowledge, but also the improvement of artistic literacy, which is the improvement and development of the comprehensive qualities of moral, intelligent, physical, aesthetic and labour. In order to better implement quality education, cultural education and art education should be carried out with both hands, using the golden age of students' artistic thinking development. Aiming at the current deficiencies in vocal music education in colleges and universities, and combining the characteristics and preferences of students under the development of the times to formulate scientific and targeted teaching courseware, and use information technology to assist vocal music teaching, so as to better cultivate students' artistic quality and promote their overall development.

Copyright $(\underset{2}{2020}$ by author(s) and Frontier Scientific Research Publishing Inc.

This work is licensed under the Creative Commons Attribution International License (CC BY 4.0).

http://creativecommons.org/licenses/by/4.0/ 


\section{The Positive Significance of the Reform and Innovation of Vocal Music Teaching in Colleges}

Vocal music teaching is a job that requires a strong level of professional ability. Especially in the current situation of more and more frequent art exchanges around the world, it has become a problem that music educators need to pay attention to that how to combine the development of society and art with the actual situation of students for effective teaching. Vocal music teaching mainly lies in cultivating students' good perception ability, taste ability, and the ability to understand the emotional expression of vocal music works, and then further improve the students' foundation and creative ability on this basis. Therefore, there are all kinds of vocal expressions that we have seen at this stage. In the new era of informatization, in order to achieve better quality education policies and concepts, it is necessary to accelerate the reform and innovation of vocal music teaching, and actively promote vocal music in a form that is more in line with the times and closer to the reality of students. Besides, it should also effectively promote the efficient teaching of vocal music classrooms through the construction of diversified and characteristic vocal music teaching methods, to allow children to enjoy better education, and promotes the improvement of students' comprehensive quality.

\section{Shortcomings in Vocal Music Teaching in Colleges}

At present, there is still a lot of room for improvement in the level and quality of vocal music teaching in colleges and universities, which is mainly reflected in the following aspects: First, the curriculum system is outdated and backward, which cannot fully reflect the characteristics of the development of the times. The 21 st century has fully entered the information age, and many new fields have been derived. However, the vocal music curriculum system of higher vocational colleges is still the structure and mode of many years ago. For example, the phenomenon of teacher-dominance is still prominent, instillation education is still obvious, and students' participation is not high, the participation enthusiasm is not enough, the classroom atmosphere is relatively rigid and dull, which can not effectively improve students' interest in learning, resulting in insignificant teaching effects. Second, the construction of vocal education team cannot keep up with the needs of vocal education under the development of the times. Some schools' vocal music teachers have insufficient professional abilities and backward education and teaching concepts. And some schools have even one teacher who has multiple jobs, which make them exhausted and unable to seriously think about effective strategies to improve teaching quality. Third, the teaching model is backward, the method is monotonous, and the classroom education innovation is insufficient, which is difficult to stimulate students' interest in learning. The current college students have very diversified channels for obtaining resources and information, and they initially have the ability to think independently. However, the current development of vocal music education in colleges and universities blindly emphasizes skills, but ignores the differences in the methods, abilities, and carriers that different students need to learn vocal music, and it is difficult to give full play to the effectiveness of vocal music education. Fourth, personalized teaching is not enough. Higher vocational colleges are mostly general education without combining students' differences in hierarchical teaching, which leads to vocal music teaching effects that are not as expected.

\section{The Reform and Innovation Strategy of Vocal Music Teaching in Colleges}

4.1 Use information technology to reconstruct the teaching model

In the reconstruction of the teaching model, we must first change the traditional blunt and monotonous vocal music teaching model, emphasizing the subjectivity of students and the interaction between teachers and students, and changing the focus of teaching from teacher-centered to student-centered change. Teaching activities should be aimed at the personality characteristics of students under the background of the information age, and the relevant learning content should be formulated into vivid and interesting digital courseware through information technology tools, and the teaching mode should be innovative, because for students, the most important art form of vocal music is perception and the 
cultivation of creativity. So, how to deepen students' perception? This is not only relying on two ears to listen, but also with the help of information technology to interpret the versatility of vocal music. For example, using multimedia equipment to display the vocal expressions of different regions and nationalities, as well as various musical instruments. In this way, students can perceive different musical instruments and the thoughts and emotions contained in the vocal works presented. Especially with the high coverage of information technology and the internet, the thinking learning mode of students have already undergone tremendous changes. Vocal music is an invisible and intangible art in itself. If you still blindly follow the traditional teaching mode of direct instillation, it will definitely not work and will not achieve good teaching results. The use of multimedia equipment for auxiliary teaching can invigorate the classroom atmosphere, attract students' attention, and gather their scattered thinking together, which can well enhance students' learning subjectivity, and make students' self-consciousness diverge to the process of independent learning, so as to maximize the teaching interaction value.

4.2 Broaden the curriculum system to improve students' perception and appreciation of vocal music

In the new century, we emphasize quality education to cultivate students' comprehensive quality, rather than a single skill education. This is because there are certain similarities between many skills, so the curriculum system should be actively expanded. For example, vocal music and dance complement each other, forming a relationship of depending on each other. The integration of different elements can invisibly improve the students' vocal literacy, help them better master the tune and rhythm, and also play a good role in shaping the students' hearing. The combination of vocal music and dance elements is also an important part of art culture, which has a certain role in improving students' ability to perceive and appreciate beauty, and at the same time, beauty can also play a positive psychological role. Inter-disciplinary or interprofessional interpenetration and integration can not only better promote the cultivation of students' perception and appreciation of beauty, but also enrich students' knowledge content. For example, in the process of national vocal music teaching, the education work can use multimedia courseware to show the scenery of the grassland: the vast grassland, the flying geese, the flocks of cattle and sheep, the yurts dotted on the vast grassland like stars, the beautiful girls, robust guy, rough and heroic folk songs, etc. These are all displayed to the students like beautiful picture scrolls, making them feel immersive, which not only helps students understand the life habits, clothing culture, local customs and habits, but also deepen the understanding and expressiveness of national vocal music.

4.3 Innovative education model to stimulate students' interest in learning

Music is not a single element. The integration of other elements such as language, dance, singing, and natural sounds make music more complete. Therefore, the selection of teaching materials should not be limited to a fixed repertoire. Teaching should be based on the actual situation, that is, the teaching materials should be selected according to the current, on-site, and students' reality, so as to more fully mobilize students' interest. After all, the motivation for students' continuous and in-depth learning mainly comes from interest. Flexible selection of teaching materials according to the actual situation of students, or self-editing of teaching materials through students' performance in class can better enhance students' cultural literacy and thinking ability, and inspire students' passion for creation. For example, using methods like speech, reading, situation creation, and music training to optimize the vocal teaching mode, so as to enhance students' creative ability and practical ability.

4.4 Improve the comprehensive ability of vocal educators

The improvement of education quality is closely related to the comprehensive strength of educators. Therefore, improving the comprehensive ability of the vocal music education team is an important prerequisite for ensuring the quality of vocal music teaching. Schools should attach importance to the comprehensive capacity building of the vocal 
music teacher team, in-depth reform of the teaching mode, strengthen the support of hardware equipment, and plan and targeted training professional skills of vocal educators. It should also encourage them to take the initiative to accept new teaching concepts, work hard to learn new teaching methods, and adjust educational concepts in accordance with the development of the times, so as to better improve the level of vocal music teaching. Not only that, vocal music teachers also need to pay attention to their own ability development and achieve self-improvement based on the perspective of professional growth. Specifically, teachers can use their spare time to start theoretical study, explore the development and changes of vocal music, and cultivate teaching ability, so as to comprehensively improve their own comprehensive ability.

\section{Conclusions}

Vocal music is an important channel for expressing emotions and an important part of art culture. The integration of different vocal elements can invisibly improve the students' musical literacy and help them better understand the connotation of the work. In the new era of vigorously advocating quality education, the vocal music education model is reformed, and advanced education methods are used to continuously innovate teaching methods, making the classroom atmosphere more relaxed and pleasant, and no longer limited by the traditional indoctrination teaching model. At the same time, the content of vocal music education is more diversified, and students' practice and participation are emphasized to inspire students' creativity and enhance students' artistic quality.

\section{Conflicts of Interest}

The author declares no conflicts of interest regarding the publication of this paper.

\section{References}

[1] Peng X.S. and Cao J. (2020). Research on the Current Situation and Reform Strategy of Vocal Music Teaching in Contemporary Colleges and Universities_C Comment on Research on Innovation Approach and Development Trend of Vocal Music Teaching in Colleges and Universities. Research in Educational Development, (10):2.

[2] Wen S.P. (2018). Research on the Reform and Innovation of Vocal Music Teaching Methods in Normal Universities_—Focusing on the Fusion of National Singing and Bel Canto. Dazhong Wenyi, (14): 179.

[3] Li Y.L. (2018). Researches on Reform and Innovation in Vocal Music Teaching in Colleges. The Artists, (10):126.

[4] Cheng R.X. (2019). Effective Ways of Reform and Innovation of Vocal Music Teaching in Colleges. Home Drama, (11):183.

[5] Jiang Q. (2019). Explore the use of interactive teaching methods in college vocal music teaching. New Silk Road: Midterm, (09):74.

[6] Lou X.L. (2020). The Innovation and Development of Vocal Music Teaching in Colleges and Universities under the Diversified Background_Comment on Research on Vocal Music Teaching and Music Education in Colleges and Universities. Chinese University Science \& Technology, (03):113. 